\title{
Web site management: making a Web site more visible
}

\author{
Margaret van Steenderen \\ Commerce Quest \\ Margaret.vanSteenderen@CommerceQuest.co.za
}

\author{
Contents \\ 1. Introduction \\ 2. Overall view of the site \\ 3. Content is king \\ 4. Search engines \\ 5. Launching the site \\ 6. Advertising on-line \\ 7. Reminders \\ 8. Keeping a record \\ 9. Follow up \\ 10. Conclusion \\ 11. Summary of useful sites \\ 12. References
}

\section{Introduction}

There has been a big push for businesses to produce Web sites and be part of the Internet. However, a Web site is not worth much without traffic. There is no one 'big bang' way to promote a site. There are lots of little steps, and these should all be considered. This is a time-consuming and ongoing process, despite the fact that there are multiple tools available for assistance. However, after initially spending a fair amount of time and money on a Web site, it is wasted if the site is not promoted.

What does it mean to make the Web site more 'visible'? According to Merriam-Webster (On-line: 2000), the word 'visible' means:

- Capable of being seen (accessible) Exposed to view Capable of being discovered or perceived Devised to keep a particular part or item always in full view or readily seen or referred to This article covers the above. That is, the importance of making the site accessible (capable of being seen); how to make sure that the site is 'exposed to view' through advertising; that the site will be capable of being discovered (mainly through search engines) and how to keep the site in full view.

\section{Overall view of the site}

The overall view and the mission of the site are established first. These include:

- Who the target audience is

- What products will be developed and delivered

- What the business objectives are. 


\subsection{Target audience}

Everything needs to start with a target audience. If there is not a specific target audience then why bother to start the site? Some companies do more damage by getting onto the Internet because they 'should' without thinking through who will be using the site and why. Who the target audience is will impact significantly on the type of site promotions that will be carried out. If it is a site offering a service or selling a product that requires a more general audience, then advertising will cover a wider base - like using a banner on Yahoo or television advertisements. If the audience is more specialized then only related sites would be used for advertising, such as advertisements placed in specific trade magazines.

\subsection{Target product}

Web sites are generally centred on a target product. Web sites typically offer a combination of goods and services. Goods may be any content, information, or commodity that might be stored by the site and delivered electronically. Services mean the methods by which these goods are delivered (Elderbrock et al. 1997:67). Elderbrock et al. go on to identify three ways that the Web is related to a company's standard products:

- Conventional - existing products, where the Web is the delivery channel (e.g. software distributed on-line; electronic brochures)

- Extended - enhanced or adapted products due to the Web being used as the medium (e.g. a tracking service or on-line customer service centre)

- Original - new goods with the Web as its foundation (e.g. new electronic publication).

\subsection{Business objectives}

'In the midst of competitive pressure to create a Web site presence and technological pressure to make use of all the latest advances, it is surprisingly easy to lose sight of a simple but critical question: Why does the company want a Web site?' (Elderbrock et al. 1997:72). Elderbrock et al. divide the business objectives of Web sites into direct and indirect revenue.

Direct revenue includes advertising, sales, membership and subscriptions and technology licensing (Elderbrock et al. 1997:72). If the site will pull enough visitors, advertising is perhaps the easiest way of generating revenue, with membership being the most difficult (due to the Internet's tradition of free information).

According to Elderbrock et al. (1997:73), indirect revenue includes lead generation and prospecting; sales and marketing support; brand awareness; product supplementation and cost reduction.

Deciding on the business objective leads to the focus of the site.

\subsection{Focus of the site}

The major focus of the site has a direct impact on the mechanisms provided for interaction. A promotional site should offer customer service, but will not have 'buy now' buttons. A content site that will provide regular updates of information should give users easy access to a mailing list. Transactional sites will have a good database running behind them, and should they be selling goods, the ability to buy an item must be easily accessible and obvious, especially to take advantage of impulse buys.

\subsubsection{Promotional sites}

According to Elderbrock et al. (1997:11), a promotional site is established to create awareness of a specific brand, stimulate demand and foster good will among customers for support. Examples of these types of sites are http://www.cocacola.com and http://ww.toyota.com. Besides creating brand awareness, the sites will come to good use for spreading information about the brand and to counter disinformation. For example, Nokia and Ericsson have discovered recently that anyone with access to e-mail can spread a rumour about a product. Both brands have used their sites as a disclaimer to a false rumour (that they were giving away free cell phones to people who forwarded a particular e-mail). 
What is important for these types of sites? Contact details should be readily available. There should also be easy access to contact someone via the site, through e-mail, forms or forums. Of course, there must be people available to handle the mail.

\subsubsection{Content sites}

'The content type of site offers users compelling entertainment or information' (Elderbrock et al. 1997:13). News sites and digital magazines fall into this category. They can be used to boost a current news service (like CNN) or be available only on the Web (e.g. the South African Journal of Information Management). The sites can be used promotionally, or to make money through subscriptions or by selling advertising.

\subsubsection{Transactional sites}

'Transactional sites sell goods, offer customer service, or conduct financial transactions' (Elderbrock et al . 1997:15). These are the most expensive sites to set up seeing that reliable databases and security are essential, as is keeping up with the latest technology available. An example of a transactional site is http://www.amazon.com. 'E-marketplaces' are springing up, where those who wish to sell goods can rent space (along with security and financial transaction processing). This really levels the playing field for sellers.

\subsection{Web identity}

'The web provides a fascinating vehicle for implementing a public identity in new ways because it is live, interactive, and global in reach' (Elderbrock et al. 1997:146). Elderbrock et al. (1997:147) provide some guidelines to keep in mind when creating a Web identity:

- Be flexible - the Web identity does not have to be the same as the corporate identity

- Be consistent - the identity should be consistent throughout the site

- Be clear - the mission and the impression you want users to have must be clear all through development, the launch and consequent advertising.

Once the overall mission of the site has been decided on, the focus is to get a target audience to the site (not just millions of visitors) and, once they have visited, to keep them coming back. It is important to decide whether the target audience is going to be international or local and to keep the demographics of the current users in mind. To generalize, the users of the Internet tend to be from high quality niche markets.

\section{Content is king}

Not only is the aim to attract visitors to the site, but also to keep users coming back and for this content is the key. A common mistake occurs where companies reproduce their paper marketing material. They load this onto a Web site and then forget about it. A visitor might be attracted once, but is not given a good reason to return. Also, if the content does not match up to the user's expectations, then their overall estimation of the company can be lowered.

Give users a reason to bookmark the site and to keep coming back. Keep the content fresh, up-to-date and changing. If possible, provide something unique that the user can come back for, for example, offering expert advice along with the product information.

\section{Search engines}

It is wise to register with search engines (SEs) once your site has been tested and is available on-line and before spending a lot of time on the launch and further site promotion. Registration is necessary so that people can find the site. For example, they might remember your company name but not the address. So it should be available to them should they use a search engine. Before submitting to sites ensure that all of the links work. Work out which keywords are appropriate for the site and make sure 
that they are available in meta-tags. Try to ensure that the site is 'search engine friendly'. For example, have robot tags, which tell the search engine's robots how deep they can index and how often to come back.

There are various ways of registering with search engines:

- The Webmaster can submit the site by hand to each search engine

- He/she can consider whether automatic submissions are worth the cost (many of which 'guarantee' ranking)

- He/she can try the free submission sites available (which usually do not 'guarantee' ranking).

Take some time to look at Web sites such as:

- Search Engine Watch (http://www.searchenginewatch.com/), which explains in detail how the different search engines really work, and helps with ways to get higher rankings in the searches (ranking is discussed in the next section)

- Promotion World (http://www.promotionworld.com/tutorial/300.html is the section specific to submitting to search engines), which provides an overview on how to submit to search engines, along with tips on how to submit to specific search engines, such as Infoseek, AltaVista, Excite and Hotbot, to name a few.

\subsection{Ranking}

Search Engine Watch explains that when a topic is run in a search engine, the 'matches will be ranked, so that the most relevant ones come first'. This way the first few sites that the user has a look at will contain the most pertinent information. Your site therefore comes in the first 10 to 20 hits, specifically within the site's area of expertise.

The problem with ranking, though, is that search engines have many different ways of applying ranking criteria. Make sure your meta-tags are complete with viable and applicable keywords. Also, take the time to check the categories in the directories and make sure that your site is listed in the applicable categories. An old trick, not worth doing, is to put in XXX (adult content sites should put $\mathrm{XXX}$ in) to try to get more hits; many search engines will automatically exclude the site if this is done when not valid.

Because there are so many search engines, it is often worthwhile considering using one of the many tools available on the Web to submit the site automatically to a batch of search engines. (Please note that this will not work for all search engines, for example, Yahoo should be submitted by hand). The following are some options and examples.

\subsection{Free search engine submission}

\section{AddMe! - www.addme.com}

This sites submits to 30 search engines (Alta Vista; WebCrawler; Lycos Northern Light; Excite; Google; Starting Point; InfoSeek; DirectHit; HotBot; Snap!; Scrub The Web; AllTheWeb; Galaxy; NerdWorld; Alexa; Jayde; REX; Matilda; Anzwers; What-U-Seek; National Directory; InfoSpace; Pronet; USA On-line; Magellan; MallPark; Infohiway; What's New; SearchHound) for 'free'. In exchange, they want a button put onto your Web site.

The AddMe! Site also has a very useful free bi-weekly newsletter with tips for site promotion and various other free tools available (including a statistics tracker - see Keeping a Record, section 8 below).

\section{Self Promotion - http://selfpromotion.com}

The search engines and directories are too numerous to list here. Once registered with the site, it takes you through various steps to automatically register. What it also does is list the SEs that you need to manually register with and gives a facility to go back and mark in your report (which can also be emailed to you) that you have manually registered with the site. It also provides information on each SE and directory listed so that you can decide whether you wish to register there are not. This is an incredibly useful tool - just take some time to go through the tutorial first. For a small 'donation' they 
make further tools available and you can voluntarily put a button on your site. This site also allows you to apply for awards (see section 6.3 below).

\subsection{Paid for search engine submission}

Web Position Gold - www.Webposition.com

Web Position Gold has received numerous awards (including ZDNet's editor's choice). Web Position will analyse your current pages, generate the needed HTML and submit your site to the SEs. You can download a free 30-day trial service, which works with a few search engines. Alternatively the costs (as at August 2000) are \$149 for the standard edition or \$349 for the professional edition (aimed at Webmasters looking after multiple domains with additional reporting features). Should the funds be available, it is worth the investment.

\section{Launching the site}

Once the site has been developed, tested, submitted to search engines and is live the next step is launching the site. The site should also be included on all printed mediums available (e.g. letterheads, business cards and documents for distribution). Off-line promotions should be ongoing; the Internet is not the only medium available to advertise a site.

The more traditional ways of launching a product (or service) that can be used are:

- Press releases (paper and electronic)

- Sponsorships

- Radio, newspaper, TV and magazine advertisements

- Posters

- Competitions

- Promotional gifts

There are quite a few options for launching and then advertising the site on-line, which are covered below.

\section{Advertising on-line}

\subsection{Banners}

Banner ads are the most used advertising on the WWW at the moment. Should banner ads be applicable, they need to be developed. The standard size is 480 x 60 pixels and no greater than $12 \mathrm{~K}$. They can be animated or static (the animation of course adds to the download size). It then needs to be decided which sites are appropriate for the banners. The position of the banners is important; they must be in a position where they can be seen. It is important to always keep the Web identity in mind when designing the banner advertisements and when deciding on which sites to place them.

Banner space can either be paid for, or banner exchange programs can be used. Some sites offer free services on condition that there is a link to their site and often include a banner that can be used. One example of a banner exchange site is:

- http://adnetwork.bcentral.com/http://www.bannerfocus.com/http://www.1bannerexchange.com/

When considering a banner exchange, always read the small print. For example, some will offer the first 500 imprints for free, and will charge thereafter.

\subsection{On-line sponsorship}

On-line sponsorship is where your company sponsors a Web site or a portion of a Web site. In return, 
there is a link provided to your site or possibly a banner. A reason for on-line sponsorship could just be community awareness. For example, the site you are sponsoring is not directly linked to your business, but you are supporting a non-profit organization. Alternatively, the sponsoring could be in exchange for advertising space. For example, CommerceQuest sponsors sections on business-related sites such as DigitalPlanet and ITWeb and receives a certain amount of space and advertising in return.

\subsection{Awards}

Awards range from the more serious 'business' awards to 'fun and funky' awards. Some awards are of course more coveted than others. The advantages of awards are that they confirm the content of the site, they assist others in determining the quality of your site and the awards sites add links to your site if an award is given. Try to only apply for those that you feel are applicable. SelfPromotion.com provides some useful criteria, for example:

- Solid HTML

- Excellent content

- Good page design

- Coolness

- Fun

- Weirdness

- Fast loading

- Technical expertise

- Creativity

- Good graphics

- Web resource

- Educational site

Sites that provide links (and assistance) with award sites are:

- http://www.123Webmaster.com/Site_Promotion/Awards/ - provides a list of links

- http://selfpromotion.com - if you have contributed. The Webmaster first evaluates your site and then, if applicable, makes awards available

- http://www.redrival.com/awardsubmit// bulk submission for multiple awards.

\subsection{Links from other sites}

It is worthwhile browsing for other sites with similar interests to yours and requesting that they provide a link to your site, especially if they have a 'links page'. One way to check site popularity is with www.addme.com (checks with AltaVista; Infoseek and Google). What Addme checks for is the number of other sites referencing yours. At times there may be a request for a reciprocal link, so keep this in mind when requesting that other sites provide a link to yours.

\subsection{E-mail}

E-mail can be a powerful tool for promoting a site and for reminding people with whom you are in contact that the site is around. Most e-mail packages allow a 'signature file'. This is a small piece of text section automatically put at the end of each e-mail, providing contact details and of course, the Web site address. When sending out an e-mail providing information, do not forget that the 'PS' section is the most read part of an e-mail. So if there is a new promotion, or important information, try adding it as a postscript.

Always make sure that if someone sends an e-mail from the site, it is answered as promptly as possible, regardless of how relevant the e-mail potentially is to the business. It might also be worthwhile using an 'auto-responder'. This is a piece of software that monitors incoming e-mails and automatically sends a response thanking the person for the contact and assuring them that someone will be in contact with them.

\subsection{Some other methods}




\subsubsection{Multiple URLs}

It is often worthwhile registering multiple Uniform Resource Locators (URLs) when registering the main address of the Web site. For example, register common mis-spellings of the original site name. Also, for example, if the site sells books, consider registering names such as www.books.co.za (already registered to Exclusive Books, this is just an example), which will then point to your site.

\subsubsection{Cross marketing}

Cross-market with another Web site, that is, promote their site and in return they will promote yours. It might be worthwhile to join the 'big boys'. They might want access to your site's content and this will give your site access to their customer base. This can be seen with sites such as e-Bay where people provide their products through them, and in return have access to their customer bases. Many of the advertisements in e-Bay have links to homepages.

\subsubsection{Web rings}

Web rings exist where like-minded sites provide links to other like-minded sites. They can be a community of sites and homepages with a common theme, linked together through the Web ring banners. Web rings have some potential but, again, keep your Web identity in mind; it might not fit in with all the sites in a Web ring. Also, some Web rings are badly maintained, so other sites may slip in, unwittingly associating yours with theirs. An example of a psychology Web ring can be found at http://www.sar.bolton.ac.uk/Psych/Main/WebRing.htm.

\subsubsection{Discussion groups/newsgroups}

The site can be advertised within the relevant discussion groups or newsgroups. However, before doing this, ensure that the groups are relevant. For example, do not advertise computer training in a newsgroup dedicated to cats. Seriously, this kind of thing happens, and the advertiser usually just winds up getting banned. Also, it is polite to contact the administrator of the newsgroup to ensure that they do not mind if an advertisement is placed, as sometimes there will be a small fee.

\subsubsection{Incentives}

Get existing users to sign up people they know by offering them something in return. For example, DigitalPlanet offers loyalty points which can be used for discounts; E-Pages offers commission so that once a subscriber has signed up four other subscribers, his/her listing is free.

\section{Reminders}

It is essential to remind visitors of the site. The visitor's details need to be captured by one of the various means available. The reminders can be:

- An automatic announcement once the site is updated

- Specific announcements (with further details on the site)

- A regular newsletter

- A reminder service of special dates (especially if the site offers gifts or flowers)

- Recommendations (for specific products if a client profile is available)

- Games and contests

- On-line forums.

\section{Keeping a record}

The amount of 'hits' (or site traffic) needs to be established. The type of report that is needed must tie in with the goals of the site. For example, for selling advertising space, the direct number of hits is important. For selling it is important to note how the site is used, what products the browsers are looking at and which ones are being missed (perhaps they are too far down). If an ISP is hosting the site, the types of logs could be restricted by what the ISP can provide and this is a consideration before choosing an ISP. Most Web servers keep a log of user activity; alternatively there is software for keeping a log that can be run in the background. It is difficult to grow a site without a record of what users are looking at, whether they are first time or repeat visitors and how many hits are coming in on a 
monthly basis. A useful site providing an analysis of 'hits' is http://www.livestat.com/SiteStats.htm.

\section{Follow up}

The Internet also provides an opportunity for fairly cheap, mass marketing. Again, keeping a record of the hits that are generated by various marketing campaigns is essential to establish which are the successful mailing lists. Once the mass marketing campaign has been established, one-to-one marketing can be established and relationships with users built up. An automatic response should be sent to acknowledge receipt of a reply; thereafter a person must answer any questions that might have arisen or highlight services that can be provided. Amazon is constantly used as an example due to their success in tracking customer information. Their site is very driven to being personalized for individual users. Users are 'the crown jewels, and they know it'.

\section{Conclusion}

In conclusion, let us take the components of the definition of visibility and see how they can be achieved:

- Capable of being seen. This covers making sure that the site is accessible. Ensure that the applicable URLs are registered. Also make sure that the site is available 24 hours a day, 7 days a week, 365 days a year.

- Exposed to view. Accomplish this through:

○ Using the URL on everything

○ Advertising

- Site sponsorship

- Banner exchanges

$\circ$ Web rings

○ Linking to other sites.

- Capable of being discovered. Make sure that the site is registered with search engines, directories and the relevant business directories.

- Keep in full view. Keep the content fresh and up to date, giving people a reason to bookmark and return to the site. Also, use reminders such as newsletters to encourage people to come back.

\section{Summary of useful sites}

\section{Search engine information:}

- http://www.searchenginewatch.com/

- http://www.promotionworld.com/tutorial/300.html

Free search engine submission (and general help with site promotion):

- http://www.addme.com

- http://selfpromotion.com

\section{General site promotion:}

- http://www.123Webmaster.com/Site_Promotion/

Paid for search engine submission:

- http://www.Webposition.com 


\section{Banner exchanges:}

- http://adnetwork.bcentral.com/http://www.bannerfocus.com/http://www.1bannerexchange.com/

Awards:

- http://www.123Webmaster.com/Site_Promotion/Awards/

- http://selfpromotion.com (If you have contributed)

- http://www.redrival.com/awardsubmit/

\section{Hits analysis:}

- http://www.livestat.com/SiteStats.htm

\section{References}

1. 123Webmaster.com. 2000. Promotion guides. [On-line]. Available WWW: http://www.123Webmaster.com/Site_Promotion/Promotion_Guides/

2. Add me. 2000. Newsletters. [On-line]. Available WWW: http://www.addme.com/

3. Elderbrock, D., Ezor, J., Dalton, L. and Weissberg, J. 1997. Producing Web hits. IDG Books Worldwide: USA

4. Melnick, J. 2000. Globalizing e-commerce. [On-line]. Available WWW: http://www-4.ibm.com/software/developer/library/globalsoft.html

5. Merriam-Webster Dictionary. 2000. [On-line]. Available WWW: http://www.m-w.com/cgibin/dictionary

6. Promotion World. 2000. Chapter 3: Submitting to the search engines. [On-line]. Available WWW: http://www.promotionworld.com/tutorial/300.html

7. Search Engine Watch. 2000. Search engine submission tips. [On-line]. Available WWW: http://www.searchenginewatch.com/Webmasters/index.html

8. Self Promotion. 2000. How to properly promote your site. [On-line]. Available WWW: http://selfpromotion.com

\section{Disclaimer}

Articles published in SAJIM are the opinions of the authors and do not necessarily reflect the opinion of the Editor, Board, Publisher, Webmaster or the Rand Afrikaans University. The user hereby waives any claim he/she/they may have or acquire against the publisher, its suppliers, licensees and sub licensees and indemnifies all said persons from any claims, lawsuits, proceedings, costs, special, incidental, consequential or indirect damages, including damages for loss of profits, loss of business or downtime arising out of or relating to the user's use of the Website. 
ISSN 1560-683X

Published by InterWord Communications for the Centre for Research in Web-based Applications, Rand Afrikaans University 